NBER WORKING PAPER SERIES

\title{
CAN MENTORING HELP FEMALE ASSISTANT PROFESSORS? INTERIM RESULTS FROM A RANDOMIZED TRIAL
}

\author{
Francine D. Blau \\ Janet M. Currie \\ Rachel T.A. Croson \\ Donna K. Ginther \\ Working Paper 15707 \\ http://www.nber.org/papers/w15707 \\ NATIONAL BUREAU OF ECONOMIC RESEARCH \\ 1050 Massachusetts Avenue \\ Cambridge, MA 02138 \\ January 2010, Revised December 2020
}

We are grateful to the many women who have volunteered their time to participate in this experiment. We are grateful to the National Science Foundation (SBE-0317755) and the American Economic Association for their financial support of the mentoring workshops and to the National Science Foundation (SES-1547054) for funding this evaluation; and to Daniel Newlon, Alice Hogan, Nancy Lutz, and John Siegfried, for supporting this program. Gwyn Loftis, and Pat Fisher provided invaluable help with the initial implementing the workshops. We thank Kasey Buckles for comments on this research. Many students have helped with data collection and analysis over the years but we would like to single out Molly Schnell and Rina Na for special thanks. This paper was revised in August, 2020 after discovering a data error. Any other errors are our own responsibility. The views expressed herein are those of the authors and do not necessarily reflect the views of the National Bureau of Economic Research.

NBER working papers are circulated for discussion and comment purposes. They have not been peer-reviewed or been subject to the review by the NBER Board of Directors that accompanies official NBER publications.

(C) 2010 by Francine D. Blau, Janet M. Currie, Rachel T.A. Croson, and Donna K. Ginther. All rights reserved. Short sections of text, not to exceed two paragraphs, may be quoted without explicit permission provided that full credit, including $(\subset)$ notice, is given to the source. 
Can Mentoring Help Female Assistant Professors? Interim Results from a Randomized Trial Francine D. Blau, Janet M. Currie, Rachel T.A. Croson, and Donna K. Ginther

NBER Working Paper No. 15707

January 2010, Revised December 2020

JEL No. A11,C93,I2,J16,J24,J44

\section{ABSTRACT}

Women continue to be underrepresented in academic ranks in the economics profession. The Committee on the Status of Women in the Economics Profession of the American Economics Association established the CeMENT mentoring workshop to support women in research careers. The program was designed as a randomized controlled trial. This study evaluates differences between the treatment and control groups in career outcomes. Results indicate that relative to women in the control group, treated women are more likely to stay in academia and more likely to have received tenure in an institution ranked in the top 30 or 50 in economics in the world.

Francine D. Blau

ILR School

Cornell University

268 Ives Hall

Ithaca, New York 14853-3901

and NBER

fdb4@cornell.edu

Janet M. Currie

Department of Economics

Center for Health and Wellbeing

185A Julis Romo Rabinowitz Building

Princeton University

Princeton, NJ 08544

and NBER

jcurrie@princeton.edu
Rachel T.A. Croson

Department of Economics and Office of the Dean

Michigan State University

Berkey Hall, Room 203509 E. Circle Drive

East Lansing, MI 48824

crosonr@utdallas.edu

Donna K. Ginther

Department of Economics

University of Kansas

333 Snow Hall

1460 Jayhawk Boulevard

Lawrence, KS 66045

and NBER

dginther@ku.edu 
Women continue to be underrepresented in academic jobs in economics. To address this problem, the Committee on the Status of Women in the Economics Profession (CSWEP) of the American Economics Association (AEA) built on an initial workshop (Bartlett and Ziegert, 2000) and established the recurring CeMENT workshops to mentor women in research careers. The national CeMENT workshop (now the Workshop for Faculty in Doctoral Programs) focused on junior female economists employed at institutions where research weighs heavily in the promotion decision. The program was designed as a randomized controlled trial, held biannually from 2004-2014. Starting in 2015 the AEA began funding the workshops every year. An interim evaluation of the first three cohorts showed that the CeMENT program increased the number of publications and the number of federal grants for treated individuals (Blau et al., 2010).

This study evaluates differences between the treatment and control groups in tenure status and academic employment, as well as publications and grants. The dataset covers all six cohorts of randomized program participants. Individuals are observed for four to fourteen years post intervention, depending on cohort, enabling us to investigate longer-run outcomes for a

reasonably large sample. Since we are primarily interested in tenure, we keep all those who, as of the fall of 2018, are observed for seven or more years since PhD. Results indicate that relative to women in the control group, treated women are more likely to stay in academia and more likely to have received tenure in an institution ranked in the top 30 or 50 in economics in the world.

\section{The Context}

Women remain underrepresented in the economics profession and progress in reducing gender disparities in economics has slowed over the past two decades (Lundberg and Stearns 2019). The annual reports of CSWEP have long documented a "leaky pipeline” from PhD programs to tenured academic jobs. A gender gap in tenure probability remains in economics 
even after controlling for productivity indicators and other factors, in marked contrast to other social sciences and the natural sciences where such gaps have been narrowed or eliminated (Ginther and Kahn 2014, Ginther and Kahn 2009, Bayer and Rouse, 2016).

Research has highlighted numerous barriers that likely contribute to women's underrepresentation. Examples include reduced access to mentoring and social networks as well as possible biases in the refereeing process (see Lundberg and Stearns 2019 for a review). Based on a professional climate survey fielded by the AEA, the past, current, and future presidents of the Association acknowledged that "many members of the profession have suffered harassment and discrimination during their careers, including both overt acts of abuse and more subtle forms of marginalization” (Blanchard, Bernanke, and Yellen 2019).

The AEA has taken a number of steps to counter these problems, including the adoption of a professional code of conduct, the establishment of a standing Committee on Equity, Diversity, and Professional Conduct (CEDPC), and the development of EconSpark, a website designed to promote information exchange and safe and respectful discussion among economists (Blanchard, Bernanke and Yellen 2019). Programs like CeMENT can complement such activities and contribute to the advancement of women in the profession by addressing mentorship and networking challenges (Buckles 2019; Blau et al. 2010).

\section{The CeMENT Intervention}

The national CeMENT workshops were designed to expose participants to role models (senior female economists), to transmit information about what it takes to be successful, and to build peer networks of female junior faculty working in similar research areas. Each workshop lasted two days and was held in conjunction with the AEA annual meetings. Participants were arranged into small groups (4-5 participants and 1-2 mentors) based on research interests. The 
workshops were widely advertised. ${ }^{1}$

Each participant circulated a research paper or other related work (like a grant proposal) before the workshop. During the workshop, the small groups met to discuss and provide feedback on each participant's work (approximately one hour for each participant). In addition, plenary sessions were held consisting of panels of the senior mentors. Topics included research and publishing, grants, professional exposure, teaching, the tenure process, and work-life balance.

Applications for each workshop significantly exceeded available slots. After incomplete or inappropriate applications were eliminated, applicants were divided into groups by research area and were then randomly assigned to treatment (participant) or control (non-participant) status within each group. In an effort to maximize access to the program, more participants than non-participants were usually selected. For example, in a group of eight, five participants and three non-participants might be selected. Both non-participants and participants were told that CSWEP had received more applicants than could be accommodated, and that participants had been randomly selected from the pool of eligible applicants. ${ }^{2}$

\section{Sample and Data Collection}

Table 1 shows the number of people from the treatment and control groups who are included in each cohort of our sample, as well as information about the seven people who were lost to follow-up (see column 5). Most people were easily traceable in public databases and supplied additional information if contacted. If we could find no record of the person's current job, we assumed that they were not in a tenure-track position. Appendix 1 provides additional

\footnotetext{
${ }^{1}$ CSWEP also ran regional workshops for economists outside research universities that were not evaluated by random assignment.

${ }^{2}$ The experiment started before the AEA had established a pre-registration data bank and was registered ex post. Institutional Review Boards at Vanderbilt and Princeton Universities approved the study design.
} 
details on our data collection methods. A larger problem is that significant numbers of those initially assigned to the control group later reapplied, and some of them were treated, as shown in column (4). In order to deal with this issue, we adopt an "intent to treat" framework in which initial assignment to treatment or control group is used to instrument whether the person was eventually treated. In addition, because 28 members of cohort 6 received their PhDs after 2011 and had to be dropped from the sample, we have re-estimated all our models using only the first five cohorts. The results (shown in Appendix 2 of this paper) are quite similar.

Information about the outcomes of individuals in our sample was collected from a variety of sources. Publications and publication dates come from Web of Science. Grants include all National Science Foundation and National Institutes of Health grants where the person is listed as the principal investigator (or co-PI). The use of these public sources enabled us to obtain consistent information on publications and grants for virtually the full sample. We note that we do not have information on articles that were forthcoming at the time tenure decisions were made nor on grants from sources other than NSF and NIH. In order to verify tenure status, we searched online curriculum vitae and university web sites with faculty listings. In cases where tenure status could not be determined in this way, we contacted individuals to ask if they had tenure. The tenure variable can be considered current as of September 2018.

Given this information, and using the rankings of journals and the world rankings of institutions in economics from Kalaitzidakis, Stengos, and Mamuneas (2003), we defined the following variables: TenureStreamJob is a job that is either on the tenure track or tenured (e.g., in a US context this would exclude lecturers). TenureRank is a tenured job. We distinguished between tenured jobs at institutions ranked in economics as 1-30, 1-50, 1-100, 1-200, or 201 
plus (unranked). ${ }^{3}$ We also investigated whether the last job reported was a non-academic job.

\section{Results}

The results of the treatment are evaluated as of fall 2018, four to fourteen years after the intervention, depending on cohort. Table 2 shows a comparison of selected pre-intervention characteristics of participants and non-participants.

Overall, most of the sample, 86-90 percent, had an academic first job. Most (90-92 percent) received their PhD from a US institution, with 73-76 percent obtaining their degrees from a top 40 institution. A substantial portion (26-30 percent) of the sample had their first job at institutions ranked in the top 40 (1-40), with 11-13 percent at top 10 institutions. While there are some differences between participants and non-participants on these dimensions, none is statistically significant.

Table 3 shows our main results. The fundamental goal of the CeMENT program was increasing the probability of holding an academic job and being in a tenured or tenure-track position. The results indicate that the treatment significantly increased the probability of women having a tenured or tenure-track position (i.e., having a tenure stream job) both overall and in an institution ranked in the top 100 in economics. The probability of having a tenure stream job was increased by 11 percentage points, or 14.9 percent relative to the mean; the probability of having a tenure stream job in a top 100 institution was increased by 15.9 percentage points or 56.4 percent. With respect to tenure itself, the treatment significantly increased the probability of a tenured job in an institution ranked in the top 30 by 6.9 percentage points (78.7 percent), and the probability of tenure in a top 50 ranked institution by 9.3 percentage points (73.8 percent). The

\footnotetext{
${ }^{3}$ Kalaitzidakis, Stengos, and Mamuneas (2003) provide world rankings of institutions in economics through 200; the 201+ category comprises institutions not included in their rankings. We added the Review of Economic Studies to their “Top 4” publications so that rank 1 here is the "Top 5.” Rank 2 publications include journals like RESTAT JOLE, JMCB, etc., and rank 3 includes other refereed journals.
} 
treatment was also estimated to have increased the probability of a tenured job at an institution ranked in the top 100 or top 200, but these effects were not significant. At the same time, participants had a significantly lower probability of having a tenured position at a 201+ (unranked) institution; this probability was reduced by 12.0 percentage points (64.5 percent). These offsetting effects help explain why the "Any Tenure" coefficient is small and statistically insignificant. The treatment also significantly lowered the probability of holding a nonacademic job by 9.5 percentage points (40.8 percent).

In Table 4, we explore possible mechanisms for the effects on tenure, focusing on the impact of the treatment on the number of pre-tenure grants and publications. Estimated effects on grants and publications are shown in columns (1)-(5). Overall, we find that treatment significantly increases the number of pre-tenure grants (by 0.150) and publications (by 1.594). Women in the treatment group have 0.216 more top five publications, 0.460 more second-tier publications, and 0.918 more third-tier publications. Note that while the effect of the treatment on the number of second-tier publications is not statistically significant at the five percent level of confidence, it is large relative to its standard error and narrowly misses significance at the 10 percent level.

How important are these treatment effects on publications and grants in producing the observed tenure results? Columns (6) and (7) examine the probability of holding a tenured job in a top 30 or 50 institution controlling for total numbers of pre-tenure publications and grants. The estimated effects of the treatment on tenure in a top 30 place declines by almost half and becomes statistically insignificant, while the estimated probability of holding tenure in a top 50 institution declines by about a third and remains marginally significant. These estimates suggest that increases in publications and grants may not be the only drivers of the treatment effects on 
tenure, at least at schools outside the top 30. Less tangible factors such as the provision of role models, networks, and information about how to navigate the system may play a role.

\section{Conclusions}

We find that the CeMENT workshops were effective in retaining women in academia, and in helping them to achieve tenure in top 50 ranked schools. It is remarkable that a two-day intervention could have had such an effect. That said, the workshops were designed to create ongoing and lasting relationships. Indeed, we know of many women who kept in touch with contacts from CeMENT for years after their workshops and used each other as a source of support and advice. Our results speak to the importance of having mentors and peer networks and suggest the difficulties many women in economics face in developing these relationships. We hope that these results will inspire others to step forward with additional ways of tackling this persistent problem. 


\section{REFERENCES}

Bartlett, Robin, and Andrea Ziegert. 2000. “Creating Career Opportunities for Female Economists: CCOFFE.” National Science Foundation Final Project Report 1997-1999, Economics Program, Division of Human Resource Development, HRD-9710136.

Bayer, Amanda and Cecilia Rouse. 2016. “Diversity in the Economics Profession: A New Attack on an Old Problem.” Journal of Economic Perspectives 30 (4): 221-42.

Blanchard, Olivier, Ben Bernanke, and Janet Yellen. 2019. “A Message from the AEA Leadership on the Professional Climate in Economics.” Published March 18, 2019. https://www.aeaweb.org/news/member-announcements-mar-18-2019.

Blau, Francine D., Janet M. Currie, Rachel T. A. Croson, and Donna K. Ginther. 2010. Can Mentoring Help Female Assistant Professors? Interim Results from a Randomized Trial." American Economic Review 100 (2): 348-52.

Blau, Francine D., Janet M. Currie, Rachel T. A. Croson, and Donna K. Ginther. 2013. "Evaluating the CSWEP Mentoring Program for Female Junior Faculty in Economics." AEA RCT Registry. December 02. https://doi.org/10.1257/rct.136-1.0.

Buckles, Kasey. 2019. “Fixing the Leaky Pipeline: Strategies for Making Economics Work for Women at Every Stage.” Journal of Economic Perspectives 33 (1): 43-60. 
Ginther, Donna K., and Shulamit Kahn. 2009. “Does Science Promote Women? Evidence from Academia 1973-2001.” In Science and Engineering Careers in the United States, edited by Richard B. Freeman and Daniel F. Goroff. NBER Science Engineering Workforce Project. Chicago, IL: University of Chicago Press.

Ginther, Donna K., and Shulamit Kahn. 2014. “Academic Women’s Careers in the Social Sciences.” In The Economics of Economists: Institutional Setting, Individual Incentives, and Future Prospects, edited by Alessandro Lanteri and Jack Vromen. Cambridge: Cambridge University Press.

Kalaitzidakis, Pantelis, Thanasis Stengos and Theofanis P. Mamuneas. 2003. "Rankings of Academic Journals and Institutions in Economics.” Journal of the European Economic Association 1 (6): 1346-1366.

Lundberg, Shelly, and Jenna Stearns. 2019. “Women in Economics: Stalled Progress.” Journal of Economic Perspectives 33 (1): 3-22. 


\begin{tabular}{cccccc} 
Cohort & Year & Treatment & Control & $\begin{array}{c}\text { Controls Who } \\
\text { Reapplied; \#Treated }\end{array}$ & $\begin{array}{c}\text { Missing \& Assumed } \\
\text { Non-Tenure Track }\end{array}$ \\
1 & 2004 & 45 & 34 & $5 ; 1 \mathrm{~T}$ & 1T; 2C \\
2 & 2006 & 36 & 27 & $10 ; 6 \mathrm{~T}$ & \\
3 & 2008 & 41 & 20 & $4 ; 3 \mathrm{~T}$ & $1 \mathrm{~T}$ \\
4 & 2010 & 28 & 19 & $5 ; 4 \mathrm{~T}$ & \\
5 & 2012 & 37 & 50 & $12 ; 10 \mathrm{~T}$ & \\
6 & 2014 & 15 & 13 & $6 ; 4 \mathrm{~T}$ & \\
\hline
\end{tabular}

Notes: Column 3 shows those who initially applied and were treated in a given cohort. Column 4 shows those who were initially assigned to the control group. Column 6 shows people who could not be located. They are included in the analysis and assumed to be in nontenure track positions. One cohort 3 control member died and was removed from the sample. Column 5 shows the number of people assigned to the control group who reapplied in a later cohort. The number after the semi-colon how many were eventually treated. 28 Cohort 6 members with $\mathrm{PhD}$ years after 2011 were dropped from the sample. 
Table 2: Balance Between Treatment and Control Samples

\begin{tabular}{|c|c|c|c|}
\hline & Treatment & Control & p-value \\
\hline Top 10 PhD Institution & 0.326 & 0.304 & 0.659 \\
\hline Top 20 (11-20) PhD Institution & 0.235 & 0.207 & 0.546 \\
\hline Top 40 (21-40) PhD Institution & 0.196 & 0.215 & 0.661 \\
\hline PhD non-US & 0.078 & 0.104 & 0.408 \\
\hline Academic First Job & 0.900 & 0.859 & 0.240 \\
\hline First Job Top 10 Rank & 0.130 & 0.111 & 0.589 \\
\hline First Job Top 11-20 Rank & 0.091 & 0.081 & 0.75 \\
\hline First Job Top 21-40 Rank & 0.083 & 0.067 & 0.582 \\
\hline PhD Year & 2005.374 & 2005.689 & 0.432 \\
\hline
\end{tabular}


Table 3: IV Estimates of Intention to Treat Effects on Outcomes

(1)

(3)

(4)

(5)

(6)

(7)

(8)

(9)

Top 100

Tenure Tenure

Any

Tenured

Tenured stream Stream Tenure Top 30 Top 50 Top 100 Top 200

\begin{tabular}{lccccccccc} 
& stream & Stream & Tenure & Top 30 & Top 50 & Top 100 & Top 200 & 201+ & Academic \\
\hline \multirow{2}{*}{ Treated } & $0.110^{* *}$ & $0.159 * * *$ & -0.053 & $0.069 *$ & $0.093^{* *}$ & 0.062 & 0.040 & $-0.120^{* *}$ & $-0.095^{*}$ \\
& {$[0.056]$} & {$[0.057]$} & {$[0.059]$} & {$[0.035]$} & {$[0.041]$} & {$[0.048]$} & {$[0.056]$} & {$[0.049]$} & {$[0.053]$} \\
Constant & $0.649 * * *$ & $0.316 *$ & -0.099 & -0.017 & $-0.267 * *$ & -0.120 & -0.013 & -0.090 & 0.252 \\
& {$[0.169]$} & {$[0.173]$} & {$[0.178]$} & {$[0.107]$} & {$[0.124]$} & {$[0.147]$} & {$[0.169]$} & {$[0.149]$} & {$[0.162]$} \\
\multirow{2}{*}{ R-squared } & 0.035 & 0.039 & 0.166 & 0.066 & 0.095 & 0.071 & 0.065 & 0.048 & 0.039 \\
Mean Dep.Var. & 0.740 & 0.282 & 0.551 & 0.0877 & 0.126 & 0.186 & 0.277 & 0.186 & 0.233 \\
\hline
\end{tabular}

There are 365 observations. Standard errors in brackets. All regressions include dummy variables for each cohort and for years 8 to $16+$ since PhD. R-squared for the first stage is 0.744 . F-statistic for the first stage regressors is $67.75 .{ }^{*} \mathrm{p}<.10,{ }^{* *} \mathrm{p}<.05, * * * \mathrm{p}<.01$. 
Table 4: IV Estimates Possible Mechanisms for Effects on Tenure

\begin{tabular}{|c|c|c|c|c|c|c|c|}
\hline & $\begin{array}{l}\text { \#Pre- } \\
\text { Tenure } \\
\text { Grants }\end{array}$ & $\begin{array}{l}\text { \#Pre- } \\
\text { Tenure } \\
\text { Pubs. }\end{array}$ & $\begin{array}{l}\text { \#Pre- } \\
\text { Tenure } \\
\text { Rank } 1 \\
\text { Pubs. }\end{array}$ & $\begin{array}{c}\text { \#Pre- } \\
\text { Tenure } \\
\text { Rank } 2 \\
\text { Pubs. }\end{array}$ & $\begin{array}{l}\text { \#Pre- } \\
\text { Tenure } \\
\text { Rank } 3 \\
\text { Pubs. }\end{array}$ & $\begin{array}{c}(6) \\
\text { Tenure } \\
\text { Top } 30 \\
\text { Place } \\
\text { Given } \\
\text { \#Pubs. } \\
\text { and } \\
\text { \#Grants }\end{array}$ & $\begin{array}{c}(7) \\
\text { Tenure } \\
\text { Top 50 } \\
\text { Place } \\
\text { Given } \\
\text { \#Pubs. } \\
\text { and } \\
\text { \#Grants }\end{array}$ \\
\hline Treated & $\begin{array}{c}0.150 \\
{[0.093]}\end{array}$ & $\begin{array}{c}1.594 * * \\
{[0.621]}\end{array}$ & $\begin{array}{c}0.216^{* *} \\
{[0.102]}\end{array}$ & $\begin{array}{c}0.460 \\
{[0.285]}\end{array}$ & $\begin{array}{c}0.918 * \\
{[0.536]}\end{array}$ & $\begin{array}{c}0.038 \\
{[0.033]}\end{array}$ & $\begin{array}{c}0.062 \\
{[0.039]}\end{array}$ \\
\hline Constant & $\begin{array}{c}-0.379 \\
{[0.283]}\end{array}$ & $\begin{array}{c}2.496 \\
{[1.885]}\end{array}$ & $\begin{array}{c}0.548 * \\
{[0.310]}\end{array}$ & $\begin{array}{c}0.202 \\
{[0.866]}\end{array}$ & $\begin{array}{c}1.745 \\
{[1.627]}\end{array}$ & $\begin{array}{c}-0.074 \\
{[0.099]}\end{array}$ & $\begin{array}{c}-0.321 * * * \\
{[0.117]}\end{array}$ \\
\hline R-squared & 0.048 & 0.097 & 0.042 & 0.067 & 0.064 & 0.227 & 0.209 \\
\hline Mean Dep.Var. & 0.274 & 7.348 & 0.321 & 2.356 & 4.671 & 0.0877 & 0.126 \\
\hline
\end{tabular}

Notes: All Table 3 notes apply. In addition, the last two columns include controls for the number of pretenure NSF and NIH grants, and the total number of pretenure publications. ${ }^{*} \mathrm{p}<.10,{ }^{* *} \mathrm{p}<.05,{ }^{* * *} \mathrm{p}<.01$. 


\section{Appendix 1: Data Collection Methods}

We collected data from several sources in order to create the analysis data on women in the CEMENT treatment and control groups. We conducted web searches for women in the CEMENT treatment and control groups in order to find their current employment status. University websites and LinkedIn allowed us to locate most in the sample. For those that we could not locate, we reached out to colleagues at their last known institution to find their current whereabouts. Whenever possible, we downloaded the most recent CVs and recorded employment history, publications and grants in an Access Database. Some individuals did not have a recent $\mathrm{CV}$, and we used sources such as LinkedIn to fill in employment records.

Given that some CVs were out-of-date or missing, we used public sources to find publications and grants. Publications, journals, and publication dates come from Web of Science. We searched for each woman by name using Python code to query the Web of Science interface and downloaded all publications associated with the name. We used publications listed on CVs, affiliations listed on publications, and the field of the journal to identify publications associated with the women in our sample. Grants include all National Science Foundation (NSF) and National Institutes of Health (NIH) grants where the person is listed as the principal investigator (or co-PI). Grant awards were downloaded from NSF and NIH award websites and matched by name, affiliation, and field of study to those in the CEMENT sample. We used the matchit routine in STATA to create fuzzy name matches, and then reviewed and verified low-quality matches. The use of these public sources enabled us to obtain consistent information on publications and grants for virtually the full sample. We note that we do not have information on articles that were forthcoming at the time tenure decisions were made nor on grants from sources other than NSF and NIH. 
In order to verify tenure status, we searched online curriculum vitae and university web sites with faculty listings. In some cases women reported the date of receiving tenure on their CVs. In other cases, we used data from the CSWEP survey of economics departments to impute tenure status for many universities. If an institution reported no untenured associate professors, we assumed that anyone reporting an associate professor rank at that institution was tenured. If a person reported that they were a full professor, we assumed that they were tenured. In cases where tenure status could not be determined in this way, we contacted individuals to ask if they had tenure and when they received it. The tenure variable can be considered current as of September 2018.

The data in the original version of this working paper contained two minor errors. First, an older version of the treatment variable and instrument was incorrectly merged onto publications and grants data. This coding mistake affects the results in columns 1-5 of Table 4. In the process of correcting that error, additional coding errors that originated when the data were hand-entered from the CVs into the database were discovered. Three people who applied twice to CEMENT were coded incorrectly. As a result, these three observations appear in both the control group and the treatment group of the sample in the previous version of the paper when they should have only appeared in the control group. These two mistakes changed the point estimates but did not affect the qualitative findings in the paper. 


\section{Appendix 2: Robustness Estimates for First Five Cohorts}

We re-estimated the results in Tables 3 and 4 in the paper, limiting the sample to the first five cohorts. We did so because approximately half of the sixth CEMENT cohort would not have sufficient time to achieve tenure. This reduced the sample size by 28 individuals. The results appear in Table A1 and A2 below. In Table A1, the magnitude and significance of the intent to treat coefficients are very similar to those found in Table 3. However, the estimated effect of having a non-academic job is no longer statistically significant.

In Table A2, the coefficient estimates are also very similar is magnitude and significance to those found in Table 4.

Table A1: IV Estimates of Intention to Treat Effects on Outcomes

\begin{tabular}{|c|c|c|c|c|c|c|c|c|c|}
\hline & (1) & (2) & (3) & (4) & (5) & (6) & (7) & (8) & (9) \\
\hline & $\begin{array}{l}\text { Tenure } \\
\text { stream }\end{array}$ & $\begin{array}{c}\text { Top } 100 \\
\text { Tenure } \\
\text { Stream } \\
\end{array}$ & $\begin{array}{c}\text { Any } \\
\text { Tenure }\end{array}$ & $\begin{array}{l}\text { Tenured } \\
\text { Top } 30 \\
\end{array}$ & $\begin{array}{c}\text { Tenured } \\
\text { Top } 50 \\
\end{array}$ & $\begin{array}{l}\text { Tenured } \\
\text { Top } 100 \\
\end{array}$ & $\begin{array}{l}\text { Tenured } \\
\text { Top } 200 \\
\end{array}$ & $\begin{array}{c}\text { Tenured } \\
201+ \\
\end{array}$ & $\begin{array}{c}\text { Last Job } \\
\text { Non- } \\
\text { Academic }\end{array}$ \\
\hline \multirow[t]{2}{*}{ Treated } & $0.105 *$ & $0.173^{* * *}$ & -0.070 & $0.076^{* *}$ & $0.102 * *$ & 0.069 & 0.039 & $-0.138 * * *$ & -0.082 \\
\hline & [0.058] & [0.058] & [0.061] & [0.036] & {$[0.042]$} & [0.051] & [0.058] & {$[0.050]$} & [0.056] \\
\hline \multirow[t]{2}{*}{ Constant } & $0.675 * * *$ & 0.273 & -0.093 & -0.051 & $-0.314^{* *}$ & -0.164 & -0.022 & -0.063 & 0.236 \\
\hline & [0.179] & {$[0.180]$} & [0.188] & [0.113] & [0.132] & [0.158] & {$[0.181]$} & [0.156] & [0.173] \\
\hline R-squared & 0.038 & 0.040 & 0.150 & 0.071 & 0.100 & 0.067 & 0.061 & 0.050 & 0.039 \\
\hline Mean Dep.Var. & 0.730 & 0.273 & 0.567 & 0.0890 & 0.131 & 0.196 & 0.288 & 0.184 & 0.243 \\
\hline
\end{tabular}

There are 337 observations. Standard errors in brackets. All regressions include dummy variables for each cohort and for years 8 to $16+$ since $\mathrm{PhD}$. R-squared for the first stage is 0.759 . F-statistic for the first stage regressors is $72.35{ }^{*} \mathrm{p}<.10,{ }^{* *} \mathrm{p}<.05, * * * \mathrm{p}<.01$. 
Table A2: IV Estimates Possible Mechanisms for Effects on Tenure. Cohorts 1-5

\begin{tabular}{|c|c|c|c|c|c|c|c|}
\hline & $\begin{array}{c}\text { \#Pre- } \\
\text { Tenure } \\
\text { Grants }\end{array}$ & $\begin{array}{l}\text { \#Pre- } \\
\text { Tenure } \\
\text { Pubs. }\end{array}$ & $\begin{array}{c}\text { \#Pre- } \\
\text { Tenure } \\
\text { Rank } 1 \\
\text { Pubs. }\end{array}$ & $\begin{array}{c}\text { \#Pre- } \\
\text { Tenure } \\
\text { Rank } 2 \\
\text { Pubs. }\end{array}$ & $\begin{array}{c}\text { \#Pre- } \\
\text { Tenure } \\
\text { Rank } 3 \\
\text { Pubs. }\end{array}$ & $\begin{array}{c}(6) \\
\text { Tenure } \\
\text { Top } 30 \\
\text { Place } \\
\text { Given } \\
\text { \#Pubs. } \\
\text { and } \\
\text { \#Grants }\end{array}$ & $\begin{array}{c}(7) \\
\text { Tenure } \\
\text { Top } 50 \\
\text { Place } \\
\text { Given } \\
\text { \#Pubs. } \\
\text { and } \\
\text { \#Grants }\end{array}$ \\
\hline reated & $\begin{array}{c}0.152 \\
{[0.095]}\end{array}$ & $\begin{array}{l}1.486^{* *} \\
{[0.623]}\end{array}$ & $\begin{array}{l}0.208^{*} \\
{[0.109]}\end{array}$ & $\begin{array}{l}0.556^{*} \\
{[0.297]}\end{array}$ & $\begin{array}{c}0.721 \\
{[0.529]}\end{array}$ & $\begin{array}{c}0.044 \\
{[0.034]}\end{array}$ & $\begin{array}{c}0.071^{*} \\
{[0.040]}\end{array}$ \\
\hline Constant & $\begin{array}{c}-0.301 \\
{[0.294]}\end{array}$ & $\begin{array}{c}2.522 \\
{[1.935]}\end{array}$ & $\begin{array}{c}0.559^{*} \\
{[0.338]}\end{array}$ & $\begin{array}{c}0.040 \\
{[0.923]}\end{array}$ & $\begin{array}{c}1.923 \\
{[1.643]}\end{array}$ & $\begin{array}{l}-0.103 \\
{[0.104]}\end{array}$ & $\begin{array}{c}-0.363 * * * \\
{[0.125]}\end{array}$ \\
\hline -squ & 0.053 & 0.095 & 0.037 & 0.069 & 0.063 & 0.232 & 0.212 \\
\hline Mean Dep.Var. & 0.279 & 7.318 & 0.338 & 2.377 & 4.602 & 0.089 & 0.131 \\
\hline
\end{tabular}

Notes: All Table A1 notes apply. In addition, the last two columns include controls for the number of pretenure NSF and NIH grants, and the total number of pre-tenure publications. ${ }^{*} \mathrm{p}<.10,{ }^{* *} \mathrm{p}<.05,{ }^{* * *} \mathrm{p}<.01$. 